\title{
"THE WIZARD OF OZ": PRÁTICAS SOCIAIS DE LEITURA E DE ORALIDADE EM INGLÊS NA VOZ DE ESTUDANTES DO ENSINO FUNDAMENTAL
}

\author{
"THE WIZARD OF OZ": LECTURA SOCIAL Y PRACTICAS DE ORALIDAD EN \\ INGLÉS EN LA VOZ DE ESTUDIANTES DE FUNDAMENTAL ESCOLAR
}
“THE WIZARD OF OZ": SOCIAL READING AND ORALITY PRACTICES IN ENGLISH IN THE VOICE OF STUDENTS IN ELEMENTARY SCHOOL

\author{
Caique Fernando da Silva FISTAROL ${ }^{1}$ \\ Isabela Vieira BARBOSA ${ }^{2}$ \\ Edson SCHROEDER ${ }^{3}$ \\ Sandra POTTMEIER ${ }^{4}$
}

RESUMO: Este artigo apresenta uma compreensão de práticas sociais de leitura e oralidade em inglês desenvolvidas a partir da obra literária "The Wizard of Oz" na voz de estudantes do $5^{\circ}$ ano do Ensino Fundamental de uma Escola Pública Municipal localizada em Blumenau/SC. Tal abordagem qualitativa assenta-se na Teoria Histórico-Cultural e nos Estudos dos Letramentos. Como instrumento de geração de dados foram utilizados um recorte de desenhos, produzidos coletivamente por um total de 16 estudantes matriculados em uma turma do $5^{\circ}$ ano do Ensino Fundamental, com idades entre 9 e 10 anos A análise dos dados aponta para a constatação de que as práticas sociais de leitura e de oralidade desses sujeitos proporcionaram não apenas a apropriação de conhecimentos científicos desenvolvidos a partir desta sequência didática envolvendo música, filme e a obra "The Wizard of Oz", mas também a ampliação do repertório cultural e linguístico dos estudantes no âmbito da interação com a língua inglesa. Considera-se, assim, importante que as aulas de línguas na Educação Básica tenham foco nos conceitos linguísticos para a interação em diversas práticas em distintas esferas sociais em que estes sujeitos circulam, assim como estejam orientadas para a reflexão sobre o repertório cultural e a dimensão intercultural dos diferentes usos da linguagem.

PALAVRAS-CHAVE: Educação Básica. Letramentos. Interação.

RESUMEN: Este trabajo presenta una comprensión de las prácticas sociales de lectura y habla en inglés desarrolladas a partir de la obra literaria "The Wizard of Oz" en la voz de estudiantes de $5^{\circ}$ grado de una Escuela Pública Municipal ubicada en Blumenau/SC. Este enfoque cualitativo se basa en la teoría histórico-cultural y en los estudios literarios. Como

\footnotetext{
${ }^{1}$ Secretaria Municipal de Educação (SEMED), Blumenau - SC - Brasil. Coordenador Curricular de Língua Inglesa e da Educação Bilíngue. Mestrado em Educação (FURB). ORCID: https://orcid.org/0000-0001-76507324. E-mail: caiquefistarol@ensinablumenau.sc.gov.br

${ }^{2}$ Universidade Regional de Blumenau (FURB), Blumenau - SC - Brasil. Doutoranda no Programa de PósGraduação em Educação. ORCID: https://orcid.org/0000-0003-1939-572X. E-mail: miss.vieira@gmail.com

${ }^{3}$ Universidade Regional de Blumenau (FURB), Blumenau - SC - Brasil. Docente no Programa de PósGraduação em Educação. Doutorado em Educação Cientifica e Tecnológica (UFSC). ORCID: https://orcid.org/0000-0001-8917-2017. E-mail: ciencia.edson@gmail.com

${ }^{4}$ Universidade Federal de Santa Catarina (UFSC), Florianópolis - SC - Brasil. Doutorado em Linguística (UFSC). ORCID: https://orcid.org/0000-0001-7328-8656. E-mail: pottmeyer@gmail.com
} 
instrumento para la generación de datos, se utilizó un conjunto de dibujos producidos colectivamente por un total de 16 alumnos matriculados en una clase de $5^{\circ}$ de Primaria, con edades comprendidas entre los 9 y los 10 años. El análisis de los datos apunta a la comprobación de que las prácticas sociales de lectura y habla de estos sujetos proporcionaron no sólo la apropiación del conocimiento científico desarrollado a partir de esta secuencia didáctica que involucra la música, la película y "The Wizard of Oz", sino también la ampliación del repertorio cultural y lingüistico de los alumnos en el contexto de la interacción con la lengua inglesa. Así, se considera importante que las clases de lengua en la Educación Básica tengan un enfoque de conceptos lingüisticos para la interacción en diversas prácticas en los diferentes ámbitos sociales en los que circulan estos sujetos, además de estar orientadas a la reflexión sobre el repertorio cultural y la dimensión intercultural de los diferentes usos de la lengua.

PALABRAS CLAVE: Educación básica. Alfabetizaciones. Interacción.

ABSTRACT: This article presents an understanding of social reading and speaking practices in English developed from the literary work The Wizard of $\mathrm{Oz}$ in the voice of 5th grade students of a Public Elementary School located in Blumenau/SC. Such a qualitative approach is based on Historical-Cultural Theory and Studies of Literacies. As a tool for data generation, a collection of drawings produced collectively by a total of 16 students enrolled in a class of the 5th year of elementary school, aged between 9 and 10 years old, was used. The data analysis points to the observation that the practices reading and orality of these subjects provided not only the appropriation of scientific knowledge developed from this didactic sequence involving music, film and the work The Wizard of $\mathrm{Oz}$, but also the expansion of the cultural and linguistic repertoire of students in the context of interaction with the English language. It is considered, therefore, important that language classes in Basic Education focus on linguistic concepts for the interaction in different practices in different social spheres in which these subjects circulate, as well as being oriented to the reflection on the cultural repertoire and the dimension intercultural understanding of the different uses of language.

KEYWORDS: Basic education. Literacy. Interaction.

\section{Introdução}

Durante os últimos anos, autores como Corso e Corso (2006), Cosson (2014), Freitas e Barros (2017), Gomes (2016), Gonçalves (2017), Mayorca (2013), Oliveira (1997), Perim (2014) têm pesquisado não apenas a literatura infantil, mas também a literatura relacionada aos contos de fadas e sua influência sobre a construção de sentidos para as crianças e até mesmo sobre os processos de aprendizagem e de desenvolvimento.

Para Cosson (2014, p. 17), o ensino de literatura tem como uma das metas "tornar o mundo compreensível, transformando a sua materialidade em palavras de cores, odores, sabores e formas intensamente humanas". Trata-se, portanto, de buscar entender as 
correlações estabelecidas entre leitores com o universo literário, a construção de sentidos por meio da leitura e interpretação de palavras, frases e enunciados, o que transcende os limites de tempo e espaço, reatualizando-se com o passar das épocas, uma vez que se compreende “[...] o processo de apropriação da literatura enquanto construção literária de sentido" (COSSON, 2014, p. 67).

Isso se justifica, uma vez que, ao ouvirem as histórias, as crianças mobilizam diferentes aspectos cognitivos para a compreensão dos elementos da história, bem como mobilizam os sentimentos despertados pelo enredo através do efeito catártico produzido. Essa mobilização de diferentes recursos cognitivos e emocionais por parte das crianças é possibilitada pela mediação do professor, contribuindo, assim, para o desenvolvimento das funções psicológicas superiores (OLIVEIRA, 1997).

No caso da língua inglesa, as histórias contadas para crianças em idade escolar trazem contribuições para a apropriação das línguas estudadas (seja portuguesa ou adicional), amplia o vocabulário e possibilita ainda à criança refletir e se imaginar dentro da perspectiva da história trabalhada. Esses fatores contribuem para a aprendizagem da criança com destaque para a relação entre imaginação e criação (VIGOTSKI, 2001; 2007; 2010a; 2010b). Além disto, de forma pontual, atuam no aprimoramento e exercício de leitura e de oralidade, uma vez que a expansão do vocabulário, os conhecimentos fonéticos, de pronúncia e de escrita estão diretamente ligados com a interação em práticas de leitura e oralidade. Nesse sentido, quanto mais cedo a criança tiver contato com histórias contadas na esfera escolar ou em outras esferas sociais, mais abrangentes serão as contribuições para os processos de letramentos da criança.

No presente texto, apresentamos resultados do acompanhamento e observação de uma sequência didática que teve como objetivo compreender práticas sociais de leitura e de oralidade em inglês a partir da obra literária The Wizard of Oz (BAUM, 2013[1990]) pelos discursos de 16 estudantes, com idades entre 9 e 10 anos, matriculados no $5^{\circ}$ ano do Ensino Fundamental de uma escola pertencente à Rede Pública Municipal de Ensino de Blumenau/SC.

\section{Os percursos metodológicos}

Este estudo piloto está inscrito em uma abordagem qualitativa (BOGDAN; BIKLEN, 1999), de cunho descrito-interpretativa (BORTONI-RICARDO, 2008), em que os instrumentos de geração de dados baseiam-se em um recorte de desenhos que emergem dos 
discursos dos estudantes que circulam socialmente na esfera escolar a partir dos sentidos atribuídos à obra “The Wizard of Oz” (BAUM, 2013[1990]), a partir de uma sequência didática direcionada para práticas de leitura e de oralidade em inglês.

Tal prática pedagógica assume uma perspectiva histórico-cultural (VIGOTSKI, 2007), a partir do entendimento de que o desenvolvimento dos estudantes e a ampliação cultural acontecem por meio de artefatos culturais e dos usos sociais destes, em práticas de leitura, escrita e oralidade.

No estabelecimento de premissas para uma Metodologia das Ciências Humanas, Bakhtin (2011[1979]) vai operar uma distinção entre conhecimento da coisa e conhecimento do indivíduo. Isso quando ambos são considerados objetos de uma pesquisa. Para o autor, "[o] objeto das Ciências Humanas é o ser expressivo e falante. Esse ser nunca coincide consigo mesmo e por isso é inesgotável em seu sentido e significado" (BAKHTIN, 2011[1979], p. 395, grifos do autor). Desse modo, pode-se afirmar que esta pesquisa exige que seja percebida a existência de uma relação dialógica com o sujeito da pesquisa, no caso, os estudantes. Tal consideração se ancora no que Bakhtin (2011[1979], p. 400) afirma:

As ciências exatas são uma forma monológica do saber: o intelecto contempla uma coisa e emite enunciado sobre ela. Aí só há um sujeito: o cognoscente (o contemplador) e falante (enunciador). A ele só se contrapõe a coisa muda. Qualquer objeto do saber (incluindo o homem) pode ser percebido e conhecido como coisa. Mas o sujeito como tal não pode ser percebido e estudado como coisa porque, como sujeito e o sujeito e permanecendo sujeito, não pode tornar-se mudo; consequentemente, o conhecimento que se tem dele só pode ser dialógico.

Baseando-se no aporte teórico-metodológico enunciativo-discursivo (BAKHTIN, 2011[1979]), considera-se a leitura como uma prática social, inserida numa atividade responsiva e de compreensão ativa no âmbito das relações entre leitores e autor, considerando-se o professor como mediador do processo de apropriação da leitura enquanto produção de sentidos. Considerando, portanto, a linguagem como interação entre sujeitos, com ênfase particular no conceito de gênero de discurso e adjacências, cabe assinalar que essa teoria será articulada com a concepção de sequências didáticas genebrinas de Schneuwly e Dolz (2004). Nesse sentido, para melhor situar o estudante nesse processo dialógico e dialético (BAKHTIN, 2011[1979]; FREIRE, 2019[1996]), propôs-se uma sequência didática (DOLZ; SCHNEUWLY, 2004) com o intuito de apresentar conceitos sobre o gênero discursivo conto em língua inglesa. 
De acordo com Spuldaro (2009, p. 41), “a narração, a qual tem por objetivo maior contar a história, real, fictícia ou a mescla de dados reais ou imaginários, estrutura-se na evolução de acontecimentos que se encaixam na narrativa, mesmo não mantendo relação de linearidade temporais". A partir do excerto acima, depreende-se que é assim que se apresenta o conto. Para Barthes (1985, p. 103), a "narrativa está presente em todos os tempos, em todos os lugares, em todas as sociedades".

Desse modo, busca-se privilegiar a prática de leitura como "uma atividade social e que prevaleça a produção de sentidos situados, tendo em vista a interação entre contexto-leitortexto e as relações dialógicas entre enunciados e/ou entre discursos" (GONÇALVES, 2017, p. 03). Para isso, optou-se por trabalhar uma obra literária já conhecida previamente em português pelos estudantes, intitulada $O$ mágico de $O z$ (BAUM, 2013[1990]). A obra já teve inúmeras traduções literárias e adaptações para o cinema, e vale destacar que a obra é um clássico elaborado e publicado em 1990, de autoria do estadunidense Lyman Frank Baum (1856-1919), contando, portanto, com mais de 120 anos desde o primeiro lançamento. Por clássico entende-se aquilo que o italiano Italo Calvino (1923-1985) destacou em 1993 na obra Por que ler os clássicos: é toda obra que não terminou de dizer o que tinha para dizer. A primeira edição para a língua portuguesa ocorreu em 1940, no periódico Gazeta dos Caminhos de Ferro, de Lisboa, que publicava, além de assuntos ferroviários, contos e textos literários.

Dolz e Schneuwly (2004) ressaltam que as sequências didáticas são atividades realizadas de forma sistemática com o intuito de contribuir para que os estudantes possam compreender e melhor utilizar os conceitos abordados, neste caso, envolvendo a leitura e a oralidade de The Wizard of Oz (BAUM, 2013[1990]). A escolha aconteceu em decorrência da obra em questão ser uma das primeiras acessadas no Ensino Fundamental 1, compreendida, nesse contexto, como instrumento de relação entre a língua portuguesa e a língua adicional, inglesa.

A sequência didática iniciou-se com um vídeo da cantora Lady Gaga (GAGA, 2013), vestida como a personagem Dorothy da história The Wizard of, na qual performatiza a canção-tema da adaptação literária para o cinema, "Somewhere over the rainbow". O intuito inicial dessa atividade foi apresentar a música-tema da adaptação da literatura para o cinema, por intermédio de uma cantora conhecida pela maioria dos estudantes. Este vídeo serviu como diagnóstico inicial por meio do interdiscurso entre conto, música e situcionalidade.

Em seguida, os estudantes foram solicitados para que anotassem palavras que conheciam, visando estabelecer uma aproximação docente com os seus conhecimentos 
prévios. De tal modo, perguntaram-se quais palavras haviam sido anotadas, em relação a quais verbetes que conheciam bem, como se já tinham conhecido os personagens da obra antes da atividade em questão, buscando, assim, averiguar conhecimentos acerca da obra estudada, bem como aspectos linguísticos reconhecíveis, relacionados à língua inglesa. Nesta etapa, os estudantes mencionaram já conhecerem as palavras girl, lion, heart, man, house. O desafio, para não incorrer no risco da artificialização do gênero e, portanto, sua invalidação como prática social, pode ser pensado a partir da consideração das alternativas metodológicas, descritas por Geraldi (2013[1991]), p. 160):

(a) se tenha o que dizer;

(b) se tenha uma razão para dizer o que se tem a dizer;

(c) se tenha para quem dizer o que se tem a dizer;

(d) o locutor se constitui como tal, enquanto sujeito que diz o que diz para quem $\operatorname{diz}(. .$.

e (e) se escolhem (sic) as estratégias para realizar (a), (b), (c) e (d).

Dessa forma, para que tivessem a quem direcionar um projeto de dizer (GERALDI, 2013[1991]), indagou-se se alguém era capaz de contar a história para os demais. Uma das meninas da turma contou a história. Posteriormente, o professor pediu para escreverem a história com suas palavras. Nesse momento, os estudantes foram questionados a recontarem a história, visando o exercício de um protagonismo de autores e contadores e também para avaliar até que ponto possuíam conhecimento sobre o artefato cultural, a história em si. Nesta etapa, foi também analisado como os estudantes compreenderam a história e como a relacionaram com o filme original e o vídeo da música tema, cantada por Lady Gaga (2013).

Ao longo das aulas, foram realizados jogos para a internalização de conteúdo a partir do conto de fadas. Alguns desses jogos envolviam vocábulos específicos do conto, tais como adjetivos (colors) e verbos no simple past (focando verbos regulares). Ou seja, por meio dos jogos, os estudantes refletem sobre a língua aprendida e o professor pode trabalhar aspectos linguísticos como pronúncia, gramática, vocabulário (FIGUEIREDO; ARAÚJO, 2018; SZUNDY, 2005; 2009), envolvendo letramentos em língua inglesa.

Numa etapa posterior, trabalhou-se a música "Somewhere over the rainbow" (GAGA, 2013) e a pesquisa sobre animais (pets), em função da curiosidade surgida a partir do personagem Totó, cachorrinho da protagonista da história. O objetivo do professor de língua inglesa era auxiliar os estudantes no processo de compreensão, ampliação dos novos vocábulos e das estruturas recém-aprendidas. 
Kalantzis e Cope (2005) destacam a importância da multiplicidade de mídias para a construção de uma linguagem mais crítica, mais significativa e multimodal para os estudantes. No caso da sequência didática elaborada, diferentes mídias foram utilizadas para desenvolver habilidades de compreensão auditiva, leitura e escrita em língua inglesa. Podemos mencionar, por exemplo, a utilização da música tema do filme adaptada da literatura, como uma atividade buscando a compreensão auditiva. Os jogos possibilitaram o conhecimento de estruturas gramaticais e vocabulário, focando as habilidades de leitura e de escrita.

Prosseguindo, os estudantes foram solicitados para que elaborassem desenhos sobre a história com sentenças curtas, de forma a sistematizar o conto. As sentenças foram sistematizadas pelo professor no quadro questionando o que estava estruturado de forma correta, conduzindo os estudantes a refletirem sobre o que havia sido mencionado. Importante salientar que se faz imperativo pontuar que o reconhecimento de uso de estruturas linguísticas gramaticalizadas a partir da experiência interacional dos estudantes pode ser mostrado e exposto de forma a produzir formas de reconhecimento de variações da escrita padrão na língua portuguesa. Neste processo, relacionam-se conhecimentos científicos e do cotidiano, pois ambos se integram dialeticamente e dialogicamente (FREIRE, 2019[1996]; BAKHTIN, 2011[1979]) como conhecimentos, em sala de aula, portanto, os conhecimentos cotidianos “espontâneos" não podem ser negligenciados. Isto, pois é a partir da e pela mediação de tais conhecimentos (cotidianos) que circulam na esfera escolar que se pode vir a intervir "na formação dos processos psicológicos superiores" (FACCI, 2004, p. 15), dos sujeitos na e pela mediação do professor, uma vez que o signo medeia socialmente estas interações na/pela linguagem.

Assim, após a sistematização foi solicitado que cada dupla, ou trio, escolhesse um excerto dessa produção textual do conto recontado com desenhos representativos da história. A atividade de desenhar visava à integração dos estudantes, bem como compreender, de forma palpável e concreta, o desenvolvimento gradual ao transpor os personagens, cenário e ações oralmente produzidas. Outro objetivo era aliar as práticas de leitura e oralidade à criação artística, uma vez que o professor compreende que a língua e a arte se desenvolvem em conjunto, como processos de desenvolvimento humano, em nosso caso, como percurso formativo dos estudantes ao longo da Educação Básica. Vigotski (2001) aponta que essa etapa da vida escolar da criança propicia significativa aprendizagem, com consequências sobre o desenvolvimento em virtude do momento, a que o autor se refere como "fase sensível": 
[...] a idade escolar é o período optimal de aprendizagem ou a fase sensível em relação a disciplinas que se apoiam ao máximo nas funções conscientizadas e arbitrárias. Assim, a aprendizagem dessas disciplinas assegura as melhores condições para o desenvolvimento das funções psíquicas superiores que se encontram na zona de desenvolvimento imediato (VIGOTSKI, 2001, p. 337).

Então, para finalizar, o professor trabalhou a oralidade utilizando-se a leitura das produções dos estudantes na forma de sentenças, enunciados e textos. Deste modo, explicou que tinha a intenção de elaborar um vídeo a partir dos desenhos com a leitura simultânea da obra adaptada na produção textual coletiva, envolvendo o tempo verbal selecionado, ampliação de vocabulário e a obra literária estudada. O professor ressaltou que o videocast, depois de finalizado, seria exibido para as turmas do primeiro ao quarto ano, divulgando o trabalho realizado por estes estudantes.

O videocast foi elaborado para que os estudantes não apenas socializassem os conhecimentos com as demais turmas, mas principalmente para que eles pudessem atuar mobilizando os conhecimentos sobre o gênero discursivo, sobre a obra apresentada e elaborassem sob os seus pontos de vista uma releitura da obra a partir de narrativas que lançassem olhar para:

i) [os] sons e músicas que hibridizam às imagens;

ii) ao enquadramento das imagens;

iii) às cores que compõem os quadrantes;

iv) à escolha das cenas;

v) à ordem das cenas

(DIAS; MORAIS; PIMENTA; SILVA, 2012, p. 88)

Conforme reforça Dias (2012, p. 103), assentada em Rojo (2009), trata-se de compreender e considerar práticas sociais de leitura e escrita locais (letramentos locais, vernaculares) que estes sujeitos realizam em diferentes esferas da atividade humana, promovendo o contato com letramentos oficiais, valorizados, institucionalizados e que "prepararão o leitor para a recepção, apreciação e a produção" deste gênero discursivo, conto, a partir de videocasts e da utilização de diferentes artefatos e/ou linguagens multissemióticos/ as.

Por fim, foram realizadas a leitura e a gravação das sentenças da obra literária adaptada e foi feita a montagem entre as imagens, a música Somewhere over the rainbow (GAGA, 2013) em versão instrumental e a produção lida por eles. Em forma de evento os estudantes do primeiro ao quarto ano foram reunidos na biblioteca da escola e apresentou-se a sequência didática The Wizard of Oz (BAUM, 2013[1990]). 
Após a finalização da sequência didática foi realizado um debate entre os estudantes do Ensino Fundamental I, questionando e respondendo quais eram as suas impressões sobre o vídeo elaborado pelos estudantes do quinto ano. Os estudantes do quinto ano interagiram com os colegas menores sobre os sentidos construídos e sobre os conhecimentos apropriados ao longo da sequência didática. $\mathrm{O}$ objetivo era compartilhar com os colegas e também refletir sobre a atividade desenvolvida, bem como trabalhar aspectos da fala em público.

A análise de dados ocorre a partir da produção coletiva da obra literária com base nos discursos e desenhos desenvolvidos pelos estudantes na sequência didática à luz dos Estudos dos Letramentos. Dessa forma, se articula a uma abordagem dos Estudos dos Letramentos nos aspectos da prática desenvolvida, dos artefatos e dos discursos.

Vale destacar que Street (2014) considera o letramento sob duas abordagens: o autônomo, este que se refere às habilidades individuais do sujeito (constituído por práticas sociais institucionalizadas, oficializadas) e o letramento ideológico que se refere ao exercício de práticas que envolvem leitura e escrita (práticas essas vernaculares, locais, que consideram a linguagem como subjetividade constitutiva ${ }^{5}$ do sujeito). Assim, considera-se, no primeiro conceito, o processamento de leitura, seja ele consciente ou inconsciente, que têm aparição na construção de sentidos de um texto. Muitos problemas que estudantes têm que resolver no âmbito de atividades de leitura e de escrita carecem mais do que simples existência de habilidades para serem resolvidos.

Neste sentido, o modelo ideológico (STREET, 2014) coloca ênfase na prática social articulada a sujeitos socialmente constituídos nas/pelas relações dialógicas com o outro (BAKHTIN, 2011[1979]), pois a leitura e a escrita não podem ser vistas como práticas apartadas de concepções de conhecimento, produção de identidades e formas de ser e estar no mundo, seja particularmente ou em contextos mais amplos de interação social. O modelo ideológico engloba o letramento autônomo, porém é mais amplo devido ao fato de compreender que práticas de letramentos não deixam de ser determinadas por instâncias sócio-históricas, associadas ao período e local em que ocorrem, pois se tratam de episódios que podem ser observados, se formam e constituem-se por meio das práticas sociais e dos usos da linguagem realizados pelos sujeitos. Sobre a necessidade de superar o modelo autônomo de letramento, Costa (2012, p. 921-922) menciona que:

O surgimento de novas práticas letradas ou novos letramentos reforça a necessidade de diminuir a lacuna cada vez maior entre a forma como se lê e

5 “A linguagem, enquanto processo de constituição da subjetividade, marca as trajetórias individuais de sujeitos que se fazem sociais também pela língua que compartilham" (GERALDI, 2015, p. 123). 
escreve na escola/academia e as formas como os estudantes usam a escrita e a leitura fora desse espaço. Ou seja, é necessário superar o modelo autônomo de letramento, supostamente neutro. Assumindo um modelo ideológico de letramento, ou letramento crítico, a educação pode caminhar em outra direção, pois passa a reconhecer que:

- as práticas de escrita e leitura foram e são construídas socialmente e se vinculam a relações de poder;

- as formas como se usam a escrita e a leitura no cotidiano, fora da escola, constituem práticas letradas tão importantes quanto aquelas desenvolvidas na educação formal e, portanto, o letramento escolar é uma opção dentre outras; - a ideologia perpassa toda e qualquer forma de letramento e, portanto, o letramento escolar não é neutro;

- a educação formal deve promover o multiletramento, ou seja, agenciar com igual relevância outras práticas letradas, além das tradicionais, e propiciar a reflexão crítica sobre os usos, valores e funções dessas práticas.

Compreendendo que as práticas de letramentos são percorridas por questões históricas e sociais, mediadas pela linguagem (STREET, 2014), optou-se por, ao longo da análise dos dados desse artigo, dar ênfase aos Estudos do Letramento com o intuito de compreender quais e de que forma práticas de letramentos proporcionadas pela sequência didática atuaram no processo de aprendizagem dos estudantes. Em consonância com os estudos de Street (2014), serão analisadas as práticas realizadas através da perspectiva dos multiletramentos (KALANTZIS; COPE, 2005), em que o termo associado está relacionado aos diferentes canais de comunicação e diversidade cultural e linguística. O ensino de uma língua adicional, nessa perspectiva, envolve modos de representação mais amplos do que apenas a língua-alvo, mas também o contexto de aprendizagem e dos sujeitos que são social, cultural e historicamente situados.

Desse modo, deve ser mencionado que os letramentos englobam aspectos da cultura e até mesmo de estruturas de poder em uma sociedade; consideramos, na perspectiva dos Estudos dos Letramentos, que as práticas de letramentos não consistem em habilidades técnicas e neutras de aquisição da escrita e da leitura. Ao contrário, os Estudos dos Letramentos defendem que as práticas de letramentos implicam em práticas sociais de leitura, escrita e oralidade, como poderemos ver, na seção de análises a seguir, a partir da sequência didática The Wizard of $\mathrm{Oz}$ (BAUM, 2013[1990]), objetivando possibilitar que os estudantes compreendam as práticas que envolvem a leitura e a escrita, seja a partir da escrita do conto de fadas, ou por meio de um roteiro da adaptação do filme ou, ainda, da sua música-tema. Nesse sentido, os estudantes são inseridos em práticas de letramentos (STREET, 2014) em que os sujeitos fazem uso em diferentes esferas sociais da atividade humana nas/pelas interações verbais com o outro (BAKHTIN, 2011[1979]).

\section{Análises e discussões dos registros: o que enunciam os estudantes em seus desenhos?}


A teoria Histórico-Cultural de Vygotsky (1896-1934) parte da premissa que a aprendizagem tem uma natureza social ao assinalar que a partir das interações sociais o sujeito desenvolve funções psicológicas superiores (VIGOTSKI, 2001; 2007; 2010a). Isso porque, para o autor assinalado, "o aprendizado humano pressupõe uma natureza social específica e um processo através do qual as crianças penetram na vida intelectual daqueles que as cercam" (VYGOTSKY, 2007, p. 100). Oliveira (1997, p. 23) destaca três pilares dessa abordagem teórica, dentre os quais destacamos:

[...] (ii) o funcionamento psicológico fundamenta-se nas relações sociais entre os indivíduos e o mundo exterior, as quais se desenvolvem num processo histórico; (iii) a relação homem/mundo é uma relação mediada por sistemas simbólicos.

Assim, se compreende que, para a aprendizagem de uma língua adicional, não apenas conhecimentos escolares e capacidades cognitivas são mobilizados, mas a contextualização do conteúdo às práticas sociais e os diferentes artefatos utilizados atuam como mediadores da interação em outra língua. Os contos de fadas, nesse sentido, podem ser um artefato cultural mediador dos processos de aprendizagem e aquisição de língua adicional, pois trazem de forma lúdica situações nas quais o estudante pode interagir, questionar, para, a partir dessas práticas, conforme Street (2014), “aprender letramento”, que não é simplesmente adquirir conteúdo, mas aprender como um processo, como uma ação contínua. Assim, a partir de práticas de leitura e escrita situadas em instâncias sociais de uso da linguagem, torna-se imperativo que o professor conceba e compreenda o letramento como prática social visando o aprimoramento e ampliação de capacidades de interação dos/entre e com os estudantes.

Ao criticar o que chama de pedagogização do letramento, Street (2014, p. 121) questiona: "se, como argumentamos, existem múltiplos letramentos, como foi que uma variedade particular veio a ser considerada como único letramento?”. Assim, articulados a esta perspectiva dos multiletramentos, Kalantzis e Cope (2005) compreendem que sociedade e aprendizagem devem ser incorporadas e contextualizadas, uma vez que os contextos sociais, culturais e materiais são parte da realidade do estudante, consequentemente, devem ser pensados como parte dos processos da aprendizagem. Nesta perspectiva, os autores defendem uma pedagogia que integra quatro fatores principais: Situated practice (Prática Situada); Overt Instruction (Instrução Explícita); Critical Framing (Enquadramento Crítico) e Transformed Practice (Prática Transformada) (KALANTZIS; COPE, 2005). 
Outrossim, em um primeiro momento da atividade proposta - chamada por Kalantzis e Cope (2005) de "Experienciamento ou Prática Situada" - o tema da atividade a ser realizada é introduzido, tendo como foco principal partir do conhecido e contextualizar o objetivo da atividade. Esse momento ocorreu quando os estudantes foram previamente questionados sobre seus conhecimentos anteriores relacionados ao vocabulário, ao vídeo assistido e até mesmo à história The Wizard of Oz (BAUM, 2013[1990]).

A permanência em determinado grupo social requer que organizemos informações e as internalizemos a fim de compartilhar a cultura deste grupo. Tais informações são agrupadas a partir de uma base de categorização que organiza formas de observar o mundo à nossa volta. Então, os conceitos cotidianos "espontâneos" vão dando lugar com o passar do tempo aos conceitos científicos (VIGOTSKI, 2001). Esta transformação foi objeto dos estudos de Vigotski (2001) e vale destacar que o processo de construção conceitual mais elaborado (científico) não ocorre sem percalços, sem a mediação do conhecimento na relação social com o outro.

Vigotski (2001) percebeu que conceitos novos promovem transformações nos conceitos já assimilados pelo sujeito, sendo este desenvolvimento processual iniciado na infância. No que diz respeito aos conceitos e o seu desenvolvimento na escola, as diferenças são percebidas mais rapidamente que as semelhanças, pois as reelaborações conceituais pressupõem a necessidade de conceitualização e generalizações mais avançadas, com a ação das funções intelectuais básicas (atenção deliberada, memória lógica, abstração, capacidade para comparar e diferenciar), necessárias para a formação de conceitos.

Por isso mesmo, e pelo caráter social da aprendizagem, é que percepção e linguagem são indispensáveis para a formação de conceitos a partir dos signos, que são na perspectiva bakhtiniana, carregados de ideologia (BAKHTIN, 2011[1979]). Consequentemente, Vigotski (2001; 2010b) defende a necessidade de considerar o conhecimento cotidiano que a criança traz e parte da sua realidade, como linguagem, experiências e vivências fora dos contextos formais de ensino, considerando, assim, a sua subjetividade, a sua singularidade.

Nos contextos da sequência, os estudantes foram questionados e instigados a participar, apresentando interpretações pessoais sobre a história - considerando que o caráter estritamente individual seja transpassado por instâncias socioculturais mais amplas, fazendo suas relações com o mundo onde estão inseridos e, mais adiante, realizando as atividades de desenho em grupo. Esse segundo momento, na perspectiva dos Estudos dos Letramentos, no qual os estudantes efetivamente começaram a atuar, recontando a história, é chamado por Kalantzis e Cope (2005) de "Conceituação", ou "Instrução Explícita". Os autores defendem a 
ideia de que durante o processo de Instrução Explícita não ocorre uma transmissão direta ou memorizações de conteúdo de forma repetitiva, apesar do nome. Neste momento, os estudantes são orientados para resolução de problemas mais complexos, desenvolvendo não apenas habilidades especificas, requeridas na execução da atividade, mas consciência e controle sobre a tarefa que está sendo executada (KALANTZIS; COPE, 2005).

A história da jovem Dorothy favorece, ainda, articulações da história da menina enviada para um mundo fantástico com a vida pessoal dos estudantes, em especial, pelo desejo de entender as relações com seus parentes, a conexão com seu animal de estimação e sua esfera social. Apesar de passagens mirabolantes e fantasiosas, os principais elementos conseguem ser compreendidos e ressignificados pelas crianças, além de desencadear sentimentos que possibilitam que efetuem a reconstrução da história relacionando-a com fatos de suas vidas cotidianas, desejos (SOUZA, 2001).

Para Vigotski (2001, p. 358), “o conceito espontâneo, ao colocar-se entre o conceito científico e o seu objeto, adquire toda uma variedade de novas relações com outros conceitos e ele mesmo se modifica em sua própria relação com o objeto". Na sequência didática, em um primeiro momento, possibilitou-se uma tomada de consciência com respeito à existência de conhecimentos espontâneos por intermédio do vídeo da apresentação da cantora Lady Gaga (GAGA, 2013), da história de The Wizard of Oz (BAUM, 2013[1990]) e da existência de conhecimentos mais elaborados, na forma de estruturas gramaticais e vocabulário utilizado.

Na Figura 1, apresentada a seguir, pode-se observar, por meio do desenho realizado por uma das estudantes, a projeção de sua imagem para ilustrar o fragmento do conto recontado.

Figura 1 - Estudante do $5^{\circ}$ projetando sua imagem para ilustrar o fragmento do conto recontado

Fonte: Dados da pesquisa

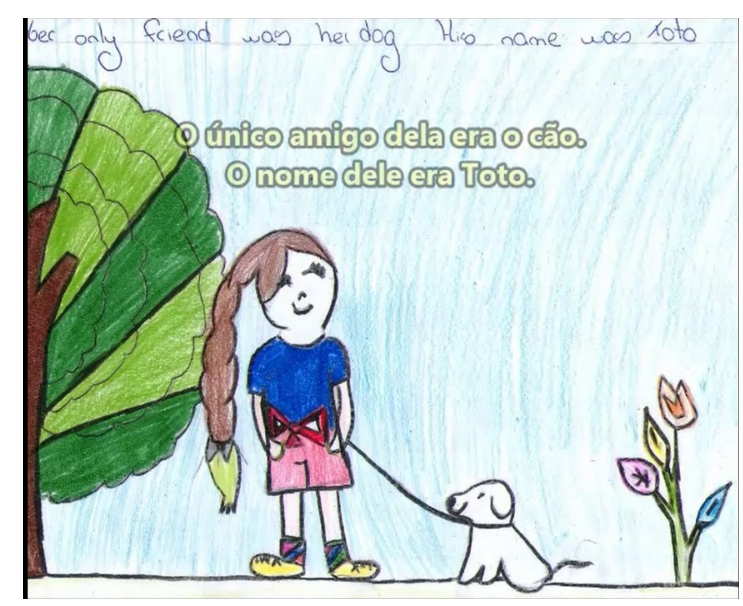


A projeção da estudante realça o que Oliveira (1997) discute sobre o processo de mediação, utilizando-se de diferentes signos, essenciais no e para o desenvolvimento das funções psicológicas superiores, como a imaginação e a criação, por exemplo. Para Vigotski (2001, p. 99), os conceitos cotidianos e científicos englobam experiências e atitudes particulares, desenvolvendo-se por caminhos distintos pelas crianças, pois "a ausência de um sistema é a diferença psicológica principal que distingue os conceitos espontâneos dos conceitos científicos". Assim, o conceito científico tem uma organização sistemática e consistente cuja construção se dá mediada por um sistema mais complexo de conceitos e pelo outro (professor e colegas).

Este processo de mediação (simbólica) conduz o estudante ao desenvolvimento das funções psicológicas superiores. Quer dizer, a internalização dos conceitos que fazem parte deste sistema mais complexo (na forma de linguagem), bem como os procedimentos que possibilitam essa internalização, conduz à elaboração de um campo semântico de significados, ou seja, um novo sistema de conceitos resultantes da dialeticidade entre o conceito espontâneo e o científico. Portanto, ocorre o desenvolvimento do que Vigotski (2010a) denomina de neoformações - novas formações que antes não existiam, ou seja, novas formas de pensamento pela criança. Esses processos pelos quais a criança passa são desencadeados quando, ao lidar com os contos de fada, projeta sua realidade e modela seus processos de pensamento.

Assim, podem ser compreendidas as possíveis contribuições da literatura para a ampliação de vocabulário, um processo que possibilita a construção de significados por parte dos estudantes. Além disso, a literatura infantil traz a possibilidade de acesso aos diferentes artefatos culturais e práticas de letramentos que, materializadas na sequência didática, visam conduzir o estudante à aprendizagem e ao desenvolvimento.

Ao utilizamos a literatura infantil em língua inglesa, as relações desencadeadas pela associação entre realidade e termos fantasiosos possibilitam uma articulação entre a realidade da criança e do mundo onde está inserida, acerca da língua inglesa e domínio das estruturas gramaticais trabalhadas, a partir do que já é conhecido. A inserção da língua inglesa ocorre de forma lúdica, a partir do conto The Wizard of Oz (BAUM, 2013[1990]), que desperta, inicialmente, o interesse da criança para, de forma posterior, relacionar o tema abordado com os conceitos e o uso da língua inglesa. 
Figura 2 - $\mathrm{O}$ estudante desenhou e pintou a casa projetando sua residência

Fonte: Dados da pesquisa

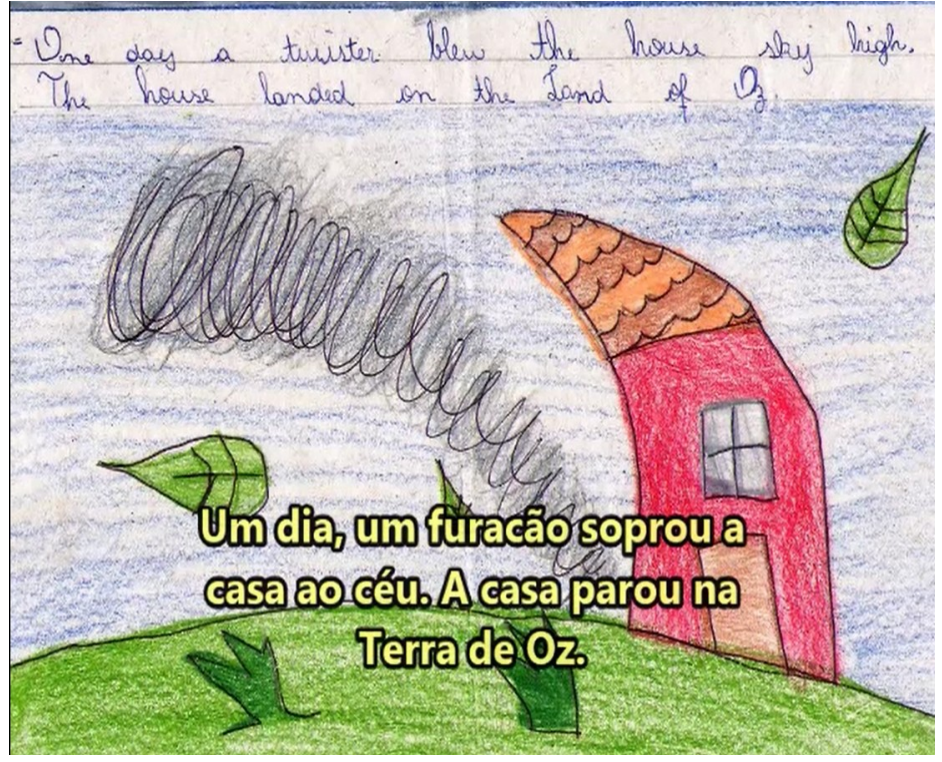

$\mathrm{Na}$ Figura 2, podemos observar que a estudante representa a casa da personagem Dorothy, projetando nela a sua própria residência, conforme posteriormente relatado. As características da experiência pessoal são levadas para a atividade em que a projeção do lar da personagem é transposta pela sua própria visão de "lar". Podemos depreender a partir do desenho da aluna a transposição de sua visão de lar para o desenho, a partir da associação do tipo de casa retratado pela aluna, com desenhos realizados sobre moradias. A aluna aproximase mais de desenhos sobre casas tradicionais, as quais ela pode ver na televisão ou em outros meios de comunicação, na sua rotina e até mesmo em seu bairro ou rua, e distancia-se da versão apresentada no clássico The Wizard of Oz (BAUM, 2013[1990]).

Neste sentido, observamos que a associação entre os conceitos espontâneos vai se articulando à formação de novos conceitos. A estudante compreende o lar de Dorothy como uma residência, mas ao transpô-lo ao papel, remete-se aos tipos de moradia que emergem de forma espontânea, ou seja, aqueles aos quais está habituada. A produção dos significados é externalizada assim, associando o texto verbal (a história contada) e o texto não verbal (a história desenha pela aluna), construindo a interpretação do enunciado, portanto, produzindo seus próprios sentidos (BAKHTIN, 2011[1979]).

O reconhecimento do conceito cotidiano de lar aponta para a construção do desenho elaborado a partir de uma associação e de uma relação entre conceitos espontâneos que vai se articulando à formação de conceitos científicos de modo a produzir a criação de significados para externalizar via associação de texto verbal e texto não verbal a construção da 
interpretação do enunciado produzido. Ou seja, aqui é possível depreender quais sentidos são atribuídos pelo estudante a partir do seu lugar de fala, de onde enuncia, do seu projeto de dizer (GERALDI, 2013[1991]) na escola e não para a escola. Ao relacionar a casa do filme à sua própria casa sinaliza para discursos dos quais se constitui e dos quais vivencia em casa, com sua família. Cabe assim, a este professor, faze a mediação daquilo que a criança traz para esfera escolar, dos conhecimentos já aprendidos com os que ainda precisa desenvolver, aprender na e pela mediação com o outro.

O reconhecimento dos elementos que compõem a relação entre o texto sinaliza para o traço do desenho no qual a casa acompanha o movimento do furacão e as folhas estão no ar simbolizando a força do vento sobre os elementos que compõem a cena. Para Talízina (1988), um novo conceito pode ser assimilado pelo contato com objetos a ele relacionados. Assim, o conceito de casa, de lar, existe na realidade sociocultural da estudante ao mesmo tempo em que sua representação se torna particular no momento em que seu projeto de dizer na escola e não para a escola aponta para elementos observáveis que traz do cotidiano (das suas vivências, das experiências, sua singularidade) para a elaboração de conceitos trabalhados e desenvolvidos em uma atividade escolar com objetivos determinados na e pela mediação do professor.

Em ambas as figuras apresentadas, os aspectos cognitivos analisados apresentam, conforme Souza (1990), os modos de reconstituição fantasiosos, os quais nas representações da história possuem elementos externos e pessoais: na Figura 1, o elemento pessoal apresentado é a projeção da protagonista no desenho, enquanto na Figura 2 pode ser notada a projeção da casa do estudante no lugar da residência da protagonista da história.

Kalantzis e Cope (2005) definem a terceira etapa dessa sequência didática como "Análise" ou "Enquadramento Crítico". Esse conceito, dos Estudos dos Letramentos, se refere ao momento em que os estudantes efetivamente analisam causas, efeitos, objetivos, razões e intenções, bem como diferentes pontos de vista. $\mathrm{Na}$ atividade realizada esse foi o momento em que refletiram sobre seus desenhos e produção textual para explicar o que foi desenvolvido, como e as motivações dos envolvidos.

Vigotski (2001) traz contribuições quando argumenta sobre a importância da sistematização teórica propiciadora de modos de organização do ensino, a fim de oferecer meios para a promoção e aprimoramento do desenvolvimento psicológico das crianças mediante ações pedagógicas que visam o ensino dos conteúdos, sobretudo na forma de conceitos (científicos). 
Ao trazer a importância dos contos de fadas para desencadear sentidos e ressignificações por parte das crianças, Souza (2001) contribui para a compreensão de que não só é possível o conto de fadas atuar como mediador da ampliação do vocabulário, pois ao serem apresentados a novos vocábulos em língua inglesa, passam a ter não apenas o suporte na língua materna, bem como a compreensão da história como suporte para ampliação do repertório cultural e da dimensão intercultural por meio do contexto. É importante mencionar que um direcionamento ao se trabalhar com instâncias de oralidade, leitura, escrita e produção de textos verbais e não verbais inter-relacionados, busca propor a criação de:

[...] contextos de produção precisos, efetuar atividades ou exercícios múltiplos e variados: é isso que permitirá aos alunos apropriarem-se das noções, das técnicas e dos instrumentos necessários ao desenvolvimento de suas capacidades de expressão oral e escrita, em situação de comunicação diversas (SCHNEUWLY; DOLZ, 2004, p. 82).

Vale destacar que, neste contexto, a mediação do professor atuará no último processo de "Aplicação" e/ou "Prática Transformada" (KALANTZIS; COPE 2005) para consolidar os conhecimentos dos estudantes e realizar os ajustes, quando necessários, ao longo desse processo. Desse modo, estudar processos psicológicos como a aprendizagem não diz respeito somente à observação de uma característica individual de cada criança, mas dela interagindo com as demais crianças de sua classe e com o professor a partir de tarefas instrucionais socialmente organizadas em torno de conhecimentos e com uma necessidade, o que confirma a constatação de existência de relações (dialéticas) entre conceitos espontâneos e científicos (VIGOTSKI, 2001; 2007; 2010a).

\section{Considerações finais}

A partir da sequência didática realizada foi possível observar o papel da literatura infantil na construção de significados e nas reconstituições fantasiosas dos estudantes. A ludicidade atua nesse sentido, auxiliando a criança a compreender o mundo a sua volta, criar um olhar crítico entre a realidade observada e, assim, desenvolver novos conceitos a partir da interação com o conhecimento científico. Foi possível observar que práticas de letramentos em língua inglesa ancoradas no ensino da leitura e oralidade nessa sequência didática elaborada a partir da obra The Wizard of $\mathrm{Oz}$ (BAUM, 2013[1990]) por estudantes do $5^{\circ}$ ano do Ensino Fundamental possibilitou a ampliação do repertório cultural, além das competências trabalhadas no componente curricular da língua adicional. 
O desenvolvimento e a apropriação da leitura e da escrita em língua inglesa são auxiliados, uma vez que esse processo lúdico desperta nos estudantes curiosidade e interesse, além das diferentes mídias utilizadas proporcionarem práticas de letramentos em língua portuguesa que são transpostas para o aprendizado na língua inglesa. O contato com os diferentes gêneros discursivos demonstra para os estudantes que eles são estáveis, embora não sejam imutáveis, e que mesmo em outra língua possuem estruturas fixas, que podem ser aproximadas, como artefatos culturais que possuem o mesmo uso.

Tal estabilidade, conforme pontuou Bakhtin (2011[1979]), é relativa e é isso que possibilita que os gêneros se transformem com o passar do tempo e se adequem a funções distintas e projetos de dizer (GERALDI, 2013[1991]) específicos. Neste ínterim, o estudo da língua a partir dos gêneros discursivos de concepção bakhtiniana:

[...] refletem as condições específicas e as finalidades de cada referido campo não só por seu conteúdo (temático) e pelo estilo da linguagem, ou seja, pela seleção de recursos lexicais, fraseológicos e gramaticais da língua, mas, acima de tudo, por sua construção composicional (BAKHTIN, 2011[1979], p. 261).

Isto pois, segundo o autor, “cada campo de utilização da língua elabora seus tipos relativamente estáveis de enunciados os quais chamamos de gêneros do discurso" (BAKHTIN, 2011[1979], p. 262, grifo do autor). Assim, não se pode esquecer que "[o]s enunciados e seus tipos, isto e, os gêneros discursivos, são correias de transmissão entre a história da sociedade e a história da linguagem" (BAKHTIN, 2011[1979], p. 268).

Outros aspectos importantes para o desenvolvimento crítico e social do estudante, como os aspectos afetivos, cognitivos e morais são propiciados pelo uso da literatura. Isso porque, na experiência em questão, através dos exemplos lúdicos, as crianças conseguiram ressignificar o que observam na história, criando conceitos e reformulando-os sobre o que é certo, errado, as causas e consequências a partir das dimensões ética, estética e política. Além disso, se torna possível que sejam estabelecidas relações afetivas com a história, uma vez que, muitas vezes, elas projetam suas próprias representações no fato estudado.

Nesse sentido, o processo de aprendizagem de língua inglesa contribui não apenas na expansão do vocabulário em língua adicional ou na compreensão de estruturas gramaticais, mas pode propiciar aos estudantes um maior contato com a literatura em língua inglesa, despertando neles uma curiosidade leitora em outro idioma. Ademais, tal atividade também propicia que os estudantes se familiarizem com gêneros orais e escritos pelo conto de fadas e com a estrutura de uma sequência didática. 


\section{REFERÊNCIAS}

BAKHTIN, M. M. Estética da criação verbal. Trad. Paulo Bezerra. 6. ed. São Paulo: Martins Fontes, 2011[1979].

BARTHES, R. Mitologias. 6. ed. Trad. Rita Buongermino e Pedro de Souza. São Paulo: Difel, 1985.

BAUM, L. F. O Mágico de Oz. Rio de Janeiro: Zahar, 2013[1990]. E-book. Disponível em: https://integrada.minhabiblioteca.com.br/books/9788537811511. Acesso em: 13 dez. 2020.

BOGDAN, R.; BIKLEN, S. Investigação qualitativa em educação: uma introdução à teoria e aos métodos. Porto: Porto Editora, 1999.

BORTONI-RICARDO, S. M. O professor pesquisador: introdução à pesquisa qualitativa. São Paulo: Parábola Editorial, 2008.

CALVINO, I. Por que ler os clássicos. Trad. Nilson Moulin. São Paulo: Companhia das Letras, 1993.

CORSO, D. L.; CORSO, M. Fadas no divã. Porto Alegre: Artmed, 2006.

COSSON, R. Letramento literário: teoria e prática. 2. ed. 4. reimp. São Paulo: Contexto, 2014.

COSTA, E. G. M. Práticas de letramento crítico na formação de professores de línguas estrangeiras. Rev. bras. linguist. apl., Belo Horizonte, v. 12, n. 4, p. 911-932, 2012. Disponível em: http://www.scielo.br/scielo.php?script=sci_arttext\&pid=S198463982012000400012\&lng=en\&nrm=iso. Acesso em: 13 dez. 2020.

DIAS, A. V. M. Hipercontos multissemióticos: para a promoção dos multiletramentos. In: ROJO, R. H. R.; MOURA, E. (Org.). Multiletramentos na escola. São Paulo: Parábola Editorial, 2012. p. 95-122.

DIAS, A. V. M; MORAIS, C. G.; PIMENTA, V. R.; SILVA, W. B. Minicontos multimodais: reescrevendo imagens cotidianas. In: ROJO, R. H. R.; MOURA, E. (Org.). Multiletramentos na escola. São Paulo: Parábola Editorial, 2012. p. 75-94.

DOLZ, J.; SCHNEUWLY, B. O oral como texto: como construir um objeto de ensino. In: SCHNEUWLY, B.; DOLZ, J. Gêneros orais e escritos na escola. Trad. Roxane Rojo e Glaís Sales Cordeiro. Campinas: Mercado das Letras, 2004.

FACCI, M. G. D. Valorização ou esvaziamento do trabalho do professor? Um estudo crítico comparativo da Teoria do Professor Reflexivo, do Construtivismo e da Psicologia Vigotskiana. Campinas: Autores Associados, 2004.

FIGUEIREDO, F. J. Q.; ARAÚJO, M. A. F. Possibilidades de aprendizagem por meio do uso de jogos em sala de aula de inglês. In: FIGUEIREDO, F. J. Q.; SIMÕES, D. (Org.).

Contribuições da linguística aplicada para a educação básica. Campinas: Pontes, 2018. p. 245-272. 
FREIRE, P. Pedagogia da autonomia: saberes necessários à prática educativa. São Paulo: Paz e Terra, 2019[1996].

FREITAS, A. W.; BARROS, A. L. E. C. Letramento literário: múltiplas linguagens na formação de leitores. In: SIMPÓSIO INTERNACIONAL DE ESTUDOS DE GÊNEROS TEXTUAIS, 9., 2017, Campinas. Anais eletrônicos [...]. Campinas: Galoá, 2017. p. 1-18. Disponível em: https://proceedings.science/siget/papers/letramento-literario--multiplaslinguagens-na-formacao-dos-leitores?lang=pt-br. Acesso em: 13 dez. 2020.

GAGA, L. Lady Gaga performing Somewhere Over the Rainbow. Applause live at Good Morning America [HD], 2013. Disponível em: https://www.youtube.com/watch? $\mathrm{v}=\mathrm{dQ} 9 \mathrm{vsZimqGE}$. Acesso em: 13 dez. 2020.

GERALDI, J. W. Ancoragens: estudos bakhtinianos. São Carlos: Pedro \& João Editores, 2015.

GERALDI, J. W. Portos de passagem. 5. ed. São Paulo: Martins Fontes, 2013[1991].

GOMES, V. V. Letramento e literatura infantil: a contribuição do conto de fadas para prática social da leitura. Almanaque multidisciplinar de pesquisa, ano 3, v. 1, n. 1, p. 106-117, 2016. Disponível em: http://publicacoes.unigranrio.edu.br/index.php/amp/article/view/3902. Acesso em: 13 dez. 2020.

GONÇALVES, R. P. A. Sequência didática tupiniquim para leitura do conto literário no ensino fundamental: um estudo bakhtiniano. In: SIMPÓSIO INTERNACIONAL DE ESTUDOS DE GÊNEROS TEXTUAIS, 9., 2017, Campinas. Anais eletrônicos [...]. Campinas: Galoá, 2017. p. 1-15. Disponível em: https://proceedings.science/siget/papers/sequencia-didatica-tupiniquim-para-leitura-do-conto-literario-no-ensino-fundamental--umestudo-bakhtiniano. Acesso em: 13 dez. 2020.

KALANTZIS, M.; COPE, B. Learning by design project group. Melbourne: Victorian Schools Innovation Commission \& Common Ground, 2005.

MAYORCA, J. P. Letramento e ensino de literatura. Revista Trías, ano III, n. 6, p. 01-14, jan. /jul. 2013. Disponível em: http://www.revistatrias.pro.br/artigos/ed-6/letramento-eensino-de-literatura.pdf. Acesso em: 13 dez. 2020.

OLIVEIRA, M. K. Vygotsky: aprendizado e desenvolvimento: um processo sócio-histórico. São Paulo: Scipione, 1997.

PERIM, S. L. Compreensão de uma fábula por meninos e meninas de 6 anos: um estudo exploratório. Rev. Psicol. UNESP, v. 13, n. 2, p. 32-40, dez. 2014. Disponível em: https://seer.assis.unesp.br/index.php/psicologia/article/view/538/493. Acesso em: 13 dez. 2020.

SCHNEUWLY, B.; DOLZ, J. Gêneros orais e escritos na escola. Trad. Roxane Rojo e Glaís Sales Cordeiro. Campinas: Mercado das Letras, 2004. 
SOUZA, M. T. C. C. Desenvolvimento cognitivo e reconstituição de contos de fadas. Boletim de Psicologia v. 50, n. 113, p. 1-19, 2001.

SOUZA, M. T. C. C. Versões de um conto de fadas em crianças de 9 a 11 anos: aspectos afetivos e cognitivos. 1990. Tese (Doutorado em Psicologia) - Instituto de Psicologia, Universidade de São Paulo, São Paulo, 1990.

SPULDARO, D. C. Palavra e imagem: diálogo entre as linguagens literária e fílmica. 2009. 117 f. (Mestrado em Letras) - Instituto de Filosofia e Ciências Humanas, Universidade de Passo Fundo, Passo Fundo, 2009. Disponível em: http://tede.upf.br/jspui/bitstream/tede/906/1/2009DaianeCasagrandeSpuldaro.pdf. Acesso em: 13 dez. 2020.

STREET, B. V. Letramentos sociais: abordagens críticas do letramento no desenvolvimento, na etnografia e na educação. Trad. Marcos Bagno. São Paulo: Parábola, 2014.

SZUNDY, P. T. C. A construção do conhecimento no jogo e sobre o jogo. Ensino e aprendizagem de LE e formação reflexiva. 2005. 295 f. Tese (Doutorado em Linguística Aplicada e Estudos da Linguagem) - Pontifícia Universidade Católica de São Paulo, São Paulo, 2005. Disponível em: https://sapientia.pucsp.br/bitstream/handle/13865/1/Paula \%20Tatianne\%20Carrera\%20Azundy.pdf. Acesso em: 13 dez. 2020.

SZUNDY, P. T. C. Jogos de linguagem como gêneros no processo de ensino- aprendizagem de LE para crianças. Trabalhos em Linguística Aplicada, Campinas, v. 48, n. 2, p. 275-294, dez. 2009. Disponível em: http://www.scielo.br/scielo.php?script=sci_arttext\&pid=S0103$18132009000200007 \& 1 n g=e n \& n r m=$ iso. Acesso em: 13 dez. 2020.

TALÍZINA, N. F. Psicologia de la enseñanza. Moscou: Progreso, 1988.

VIGOTSKI, L. S. A construção do pensamento e da linguagem. São Paulo: Martins Fontes, 2001.

VIGOTSKI, L. S. A formação social da mente: O desenvolvimento dos processos psicológicos superiores. 7. ed. São Paulo: Martins Fontes, 2007.

VIGOTSKI, L. S. Aprendizagem e desenvolvimento intelectual na idade escolar. In: VIGOTSKI, L. S; LURIA, A. R.; LEONTIEV, A. N. Linguagem, Desenvolvimento e Aprendizagem. Trad. Maria da Pena Villalobos. 11. ed. São Paulo: Ícone, 2010b. p. 103-117.

VIGOTSKI, L. S. Psicologia pedagógica. Trad. Paulo Bezerra. 3. ed. São Paulo: Editora WMF Martins Fontes, 2010a.

\section{Como referenciar este artigo}


FISTAROL, C. F. S.; BARBOSA, I. V.; SCHROEDER, E.; POTTMEIER, S. "The Wizard of Oz": práticas sociais de leitura e de oralidade em inglês na voz de estudantes do ensino fundamental. Revista Ibero-Americana de Estudos em Educação, Araraquara, v. 16, n. 3, p. 1838-1859, jul./set. 2021. e-ISSN: 1982-5587. DOI: https://doi.org/10.21723/riaee.v16i3.15134

Submitted: 10/11/2020

Required revisions: $14 / 12 / 2020$

Approved: 05/01/2021

Published: 01/07/2021 